\title{
Contraception after medication abortion should be determined by convenience and choice
}

\section{Kelly Blanchard}

\section{Correspondence to}

Kelly Blanchard, Ibis

Reproductive Health, Cambridge,

MA 02140, USA; kblanchard@

ibisreproductivehealth.org

Received 4 September 2018 Accepted 4 September 2018

\section{Linked}

- http://dx.doi.org/10.1136/ bmjsrh-2017-101928

Check for updates

(C) Author(s) (or their employer(s)) 2018. No commercial re-use. See rights and permissions. Published by BMJ.

To cite: Blanchard K. BMJ Sex Reprod Health

2018;44:235-236.
Abortion is a common experience and people seeking abortion are increasingly choosing medication abortion (abortion with medicines, most often mifepristone and misoprostol). Many women who have had an abortion will be interested in contraception services, and providing information about and access to a wide range of contraceptive methods where abortion is offered is a critical component of high quality care. Because mifepristone is a progesterone antagonist, there has been some concern that offering progestin-only methods (like progestin-only implants or injectables) at the time medication abortion drugs are taken might interfere with the effectiveness of medication abortion. This analysis from Lang and colleagues ${ }^{1}$ provides information from a large number of women who received a progestin-only injectable (depo medroxyprogesterone acetate, DMPA) at the time they received misoprostol (the second drug in the regimen, taken 24-48 hours after mifepristone). The findings are an important addition to the literature and add to the existing data that support providing contraception based on women's choice and convenience.

Although research has shown that implants inserted on the day of mifepristone do not impact medication abortion effectiveness, a study by Raymond et al recently reported that the risk of continuing pregnancy after medication abortion was higher when DMPA was administered on the day of mifepristone compared with after the abortion was complete. ${ }^{2}$ But, the increase in continuing pregnancy was small $(0.4 \%)$ and the risk of not being able to return and receive a desired injectable (and the subsequent risk of unintended pregnancy) is an important consideration. In the USA, it has been common for women to take misoprostol at home and thus documenting the impact of choosing and starting contraception on the day of mifepristone administration is critical. Despite the documented safety and effectiveness of home-use of misoprostol, in some settings-like Scotland and Wales until recently and England (through the end of this year, see https:// www.theguardian.com/world/2018/aug/ 25/use-of-second-abortion-pill-at-hometo-be-allowed-in-england)-women are required by law or regulation to return to the clinic for misoprostol. Some people seeking abortion might also prefer to wait until they take the second medication for convenience or might want more time to decide whether they want to use a method and which one is right for them. These data on DMPA administration at the time of misoprostol administration, and the fact that there was no difference in effectiveness of medication abortion regardless of type of method or no method use, indicate that women can be offered the option of starting their contraceptive method at the same time they take either the first or the second medication and, as the authors state, 'Given the data available to date, any location or timing of DMPA administration would seem reasonable based on the woman's informed choice'.

These data are also important in the larger context of innovations in access to medication abortion in contexts where abortion is largely legal or where it is legally restricted. Providing information about medication abortion via 'harm reduction' services, ${ }^{3} 4$ accessing medication abortion medicines via the internet $^{5} 6$ or with support from safe abortion hotlines ${ }^{6-8}$ and buying medication abortion medicines over-the-counter without a healthcare provider intermediary ${ }^{9}$ have all been shown to be safe and effective ways to access medication abortion in legally restricted settings, increasing access to a critical health service 
and reducing the risks and sequelae of unsafe abortion. In addition, in settings where abortion is legal, telemedicine services that connect people to providers via a video conference ${ }^{10}$ have been shown to be safe and effective, and researchers are currently assessing both direct-to-person mailing of medication abortion medicines as well as telemedicine where people seeking abortion care connect to a provider directly from their home. Information about contraception provided as part of these service modalities can assure people seeking medication abortion that they can start using a contraceptive method at whatever point during the process is convenient for them.

It is important to note that any information provided to people seeking medication abortion care-whether written or during in-person counselling-should emphasise that although contraception may be the right choice for some, the decision about whether or not to use a method should be up to the individual. High-quality care requires providing information and access to one's method of choice, and also requires that providers do not coerce people seeking care into use or choice of a particular method. Health service indicators that focus on the proportion of people leaving a service with a method or starting to use a method within a specific period of time may undermine autonomy and interfere with real choice, and stigma about unintended pregnancy and choosing abortion more than once should be addressed both in healthcare settings and in our communities.

Additional data documenting the effectiveness of starting contraceptive use when it is most convenient means people having medication abortions can be offered information about and access to the full range of hormonal methods, including progestin-only methods, whenever they decide they would like to start a contraceptive method. In addition, as advances in hormonal method delivery-like self-injected subcutaneous DMPA or the 1 year combined vaginal ring (see: http://www.popcouncil.org/news/20454), and hopefully over-the-counter access to progestin-only and combined oral contraceptives, continue to make accessing contraception more convenient, people can increasingly choose the location, method and timing of their abortion and contraception if they do not have access to a clinic or provider or would prefer not to visit a facility. We need to ensure all people have access to information about all their abortion and contraception care options and the ability to access the products they need-ensuring especially that financial, health insurance and other barriers do not limit these advances to only those who can afford them.

Acknowledgements I would like to acknowledge Caitlin Gerdts, Heidi Moseson, and Sarah Baum who provided excellent input on the content of this editorial.

Contributors $\mathrm{KB}$ developed and wrote this editorial.

Funding The authors have not declared a specific grant for this research from any funding agency in the public, commercial or not-for-profit sectors.

Competing interests None declared.

Patient consent Not required.

Provenance and peer review Commissioned; internally peer reviewed.

\section{REFERENCES}

1 Lang C, Chen ZE, Johnstone A, et al. Initiating intramuscular depot medroxyprogesterone acetate 24-48 hours after mifepristone administration does not affect success of early medical abortion. BMJ Sex Reprod Health 2018;44:2427.

2 Raymond EG, Weaver MA, Louie KS, et al. Effects of depot medroxyprogesterone acetate injection timing on medical abortion efficacy and repeat pregnancy: a randomized controlled trial. Obstet Gynecol 2016;128:739-45.

3 Briozzo L, Vidiella G, Rodríguez F, et al. A risk reduction strategy to prevent maternal deaths associated with unsafe abortion. Int J Gynaecol Obstet 2006;95:221-6.

4 Grossman D, Baum SE, Andjelic D, et al. A harm-reduction model of abortion counseling about misoprostol use in Peru with telephone and in-person follow-up: A cohort study. PLoS One 2018;13:e0189195.

5 Jelinska K, Yanow S. Putting abortion pills into women's hands: realizing the full potential of medical abortion. Contraception 2018;97:86-9.

6 Aiken A, Gomperts R, Trussell J. Experiences and characteristics of women seeking and completing at-home medical termination of pregnancy through online telemedicine in Ireland and Northern Ireland: a population-based analysis. BJOG 2017;124:1208-15.

7 Gerdts C, Hudaya I. Quality of care in a safe-abortion hotline in indonesia: beyond harm reduction. Am J Public Health 2016;106:2071-5.

8 Zurbriggen R, Keefe-Oates B, Gerdts C. Accompaniment of second-trimester abortions: the model of the feminist Socorrista network of Argentina. Contraception 2018;97:108-15.

9 Footman K, Scott R, Taleb F, et al. Feasibility of assessing the safety and effectiveness of menstrual regulation medications purchased from pharmacies in Bangladesh: a prospective cohort study. Contraception 2018;97:152-9.

10 Grossman D, Grindlay K. Safety of medical abortion provided through telemedicine compared with in person. Obstet Gynecol 2017;130:778-82. 